\title{
A cryptic species of Onchocerca (Nematoda: Onchocercidae) in blackflies (Simulium spp.) from southern California, USA
}

\author{
Guilherme G Verocai ${ }^{1,2^{*}}$, Kimberly J Nelson ${ }^{3}$, R Trey Callahann', Joseph Wakoli Wekesa ${ }^{4}$, Hassan K Hassan²
} and Eric P Hoberg ${ }^{5}$

\begin{abstract}
Background: Entomological surveillance for pathogens based on molecular screening of putative arthropod vectors such as blackflies (Diptera: Simuliidae) is becoming increasingly important. Surveillance provides a means to understand host and geographical patterns of underestimated biodiversity among North American species of Onchocerca and a pathway to identify and track expanding emergence of the zoonotic Onchocerca lupi. Herein, we have screened two blackfly species, Simulium tescorum and Simulium vittatum (s.l.), from Los Angeles County, southern California, USA for DNA of filarioid nematodes to better understand species richness and limits within the genus Onchocerca.

Methods: A total of 1056 and 378 female blackflies was collected using $\mathrm{CO}_{2}$-baited mosquito traps from March to November of 2015 and 2016, respectively. All blackflies during 2015 were individually processed for DNA extraction and PCR targeting of the cytochrome $c$ oxidase subunit 1 (cox1) of the mitochondrial DNA (mtDNA). Specimens of $S$. tescorum collected in 2016 were processed individually with heads and bodies extracted separately, whereas those of $S$. vittatum (s.l.) were processed in pooled samples with heads and bodies extracted separately. A subset of filarioidpositive samples from 2015 and all samples from 2016 were screened using a PCR targeting the NADH dehydrogenase subunit 5 (nad5) gene (mtDNA).

Results: In 2015, 356 S. tescorum (33.7\%) and 683 S. vittatum (s.l.) (64.7\%) were collected, and an additional 17 specimens were not assessed morphologically. In 2016, a total of 378 blackflies was collected. Of these, 43 (11.6\%) were S. tescorum and 327 (88.4\%) were S. vittatum (s.l.), and an additional 8 specimens were not assessed morphologically. In 2015, Onchocerca sequences were detected in $4.8 \%(n=17)$ of S. tescorum samples, and only one S. vittatum $(0.15 \%)$. In 2016, only a single $S$. vittatum pool was positive for the same cryptic Onchocerca species. In phylogenetic comparisons based on nad5, the Onchocerca sequences from California formed a clade with those isolates in white-tailed deer from upstate New York, suggesting these belong to a single widespread cryptic species.

(Continued on next page)
\end{abstract}

\footnotetext{
*Correspondence: gverocai@gmail.com

'Department of Infectious Diseases, College of Veterinary Medicine,

University of Georgia, 501 D.W. Brooks Drive, Athens, GA 30602, USA

${ }^{2}$ Department of Global Health, College of Public Health, University of South

Florida, 3720 Spectrum Boulevard, Tampa, FL 33612, USA

Full list of author information is available at the end of the article
}

(c) The Author(s). 2018 Open Access This article is distributed under the terms of the Creative Commons Attribution 4.0 International License (http://creativecommons.org/licenses/by/4.0/), which permits unrestricted use, distribution, and reproduction in any medium, provided you give appropriate credit to the original author(s) and the source, provide a link to the Creative Commons license, and indicate if changes were made. The Creative Commons Public Domain Dedication waiver (http://creativecommons.org/publicdomain/zero/1.0/) applies to the data made available in this article, unless otherwise stated. 


\begin{abstract}
(Continued from previous page)
Conclusions: An uncharacterized species of Onchocerca associated with cervid hosts was found in blackflies from southern California. Sequence data demonstrated it is likely conspecific with an unnamed species of Onchocerca previously found in white-tailed deer from upstate New York. Current data support recognition of a broad geographical distribution across North America for an apparently cryptic species of Onchocerca that is discrete from $O$. cervipedis, considered to be a typical filarioid among cervids. Our data suggest that this cryptic species of Onchocerca may infect subspecies of white-tailed deer (Odocoileus virginianus), and mule and black-tailed deer (Odocoileus hemionus) at temporal latitudes. The blackflies Simulium tescorum and S. vittatum (s.l.) (presumably, S. tribulatum) are putative vectors. Discovery of a cryptic complex indicates that species diversity and putative associations for definitive hosts and vectors of Onchocerca species in North America must be reassessed.
\end{abstract}

Keywords: Cervidae, Filarial parasites, Filarioidea, Onchocerciasis, Parasite biodiversity, Vector-borne diseases

\section{Background}

Onchocerca (Nematoda:;Filarioidea: Onchocercidae) is a genus of parasitic nematodes infecting wild and domestic ungulates, carnivores, and humans globally [1-3]. Despite the medical and veterinary importance of some species, including Onchocerca volvulus (Leuckart, 1893), the causative agent of human onchocerciasis or river blindness, and the emerging zoonotic Onchocerca lupi Rodonaja 1967, the causative agent of canine ocular onchocercosis, most species associated with domestic and wild ungulate hosts have not been directly linked to disease [1]. Species of Onchocerca are transmitted to mammalian definitive hosts by dipteran arthropod biological vectors, including species of blackflies (Simuliidae) and biting midges (Ceratopogonidae) [2] .

Onchocerca is a speciose genus encompassing 34 valid species [1]. There is evidence, however, for underestimated species richness and the potential for unrecognized cryptic diversity [4-7]. For instance, three species have been described from Japan in the last four decades, i.e. Onchocerca suzukii Yagi, Bain \& Shoho, 1994 in the Japanese serow Capricornus crispus (Temminck) [6], Onchocerca eberhardi Uni \& Bain, 2007 in the sika deer Cervus nippon Temminck [4], and Onchocerca takaokai Uni, Fukuda \& Bain, 2015 in the Japanese wild boar Sus scrofa leucomystax Temminck [5].

In addition to these observations from Asia, there is molecular evidence for a cryptic species infecting the white-tailed deer Odocoileus virginianus (Zimmermann) from North America [7]. Until recently, Onchocerca cervipedis Wehr \& Dikmans, 1935 was the only recognized species infecting wild ungulates across North and Central America, and it remains the only formally described species [8-11]. Its reported host range includes five cervids: the white-tailed deer; the mule deer Odocoileus hemionus (Rafinesque); moose Alces americanus (Clinton); elk or wapiti Cervus canadensis Erxleben; and caribou Rangifer tarandus (L.); and also, the antilocaprid pronghorn Antilocapra americana Ord [8, 10-19]. Consistent with discovery of cryptic diversity among other ungulate nematodes, $O$. cervipedis may constitute a complex of species, as it represents a geographically widespread parasite with a considerable host range. Potential species limits and diversity for Onchocerca in conjunction with host range, and geographical associations must be revisited. Transmission pathways, vector diversity and associations also require reconsideration.

Recent evidence for underestimated diversity among North American species of Onchocerca, in conjunction with the emergence of the zoonotic O. lupi, have increased interest in entomological surveillance for these parasites. Molecular-based screening of putative arthropod biological vectors, including blackflies (Diptera: Simuliidae) for DNA of filarial nematodes is a powerful methodology to reveal occurrence of cryptic diversity [20]. Herein, we have screened two blackfly species, Simulium tescorum Stone \& Boreham and Simulium vittatum (s.l.), from Los Angeles County, southern California, USA, for DNA of filarial nematodes. We provide some initial observations about diversity and geographical distribution of a poorly understood assemblage of species within Onchocerca from North America. Also, we discuss the role of these blackflies as vectors, the putative association with mule deer as definitive hosts, and provide insights about the historical biogeography of a cryptic Onchocerca species originally documented in white-tailed deer from New York [7].

\section{Methods \\ Blackfly collection}

Los Angeles County (LAC), California, is the most populous county in the USA with a population of over 10 million inhabitants in an area of $12,310 \mathrm{~km}^{2}$, with a density of 800 people $/ \mathrm{m}^{2}$. Elevation varies from sea level to $3069 \mathrm{~m}$ encompassing heterogeneous habitats supported by a Mediterranean climate with usually hot and dry summers. Surveillance was targeted in this region based on the endemic occurrence of the zoonotic O. lupi [20], and the potential occurrence of other species of Onchocerca that may be associated with mule deer 
(Odocoileus hemionus), the only endemic cervid in the region [21].

Adult female blackflies were collected through collaborations with the San Gabriel Valley Mosquito and Vector Control District (SGVMVCD) and the Greater Los Angeles County Vector Control District (GLACVCD) using mosquito day traps baited with $\mathrm{CO}_{2}$. Flies were collected from various sites by SGVMVCD, and GLACVCD personnel from March to November of 2015 and 2016.

\section{Morphological identification of blackflies}

Blackflies collected by the SGVMVCD were morphologically identified to species/species-complex level according to taxonomic keys [22], and stored frozen at -80 ${ }^{\circ} \mathrm{C}$ until analysis. Specimens collected by GLACVCD were not identified to species and stored in $70 \%$ ethanol. Voucher specimens of blackflies were not retained or archived in a museum repository due to the destructive nature of sampling that was required for molecular screening in the present study.

\section{Molecular screening for Onchocerca spp. DNA 2015 collections}

All blackflies collected in 2015 were processed individually for DNA extraction using the Qiagen DNeasy Blood \& Tissue kit (Qiagen, Valencia, CA, USA). Briefly, all flies were macerated with sterile plastic pestles within an Eppendorf tube, and homogenized with ATL buffer, and proteinase K. Samples were then incubated in a dry heat block for $45 \mathrm{~min}$ at $56{ }^{\circ} \mathrm{C}$, and then centrifuged for 5 min. at $8000 \times g$. The supernatant of each sample was transferred into new tubes. Extractions were processed in the automated, low throughput robotic workstation (QIAcube, Qiagen, Valencia, CA, USA) using the manufacturer's protocol for tissue.

Polymerase chain reaction was performed on the blackfly DNA extracts in search of the presence Onchocerca sp. DNA. Multiple genetic markers target the mitochondrial genes of filarial worms in search of Onchocerca sp. These include the NADH dehydrogenase subunit 5 (nad5) gene and the cytochrome $c$ oxidase subunit 1 ( $\operatorname{cox} 1)$ gene. The PCR protocols used for these genetic markers are listed below; GOTAQ ${ }^{\mathrm{m}}$ DNA polymerase was used in these reactions. Primers targeting the $\operatorname{cox} 1$ were: HFCOI-F (5'-TGT TGC CTT TGA TGT TGG GG-3') and HFICOI-R (5'-GGA TGA CCG AAA AAC CAA AAC AAG-3') [23]. Cycling conditions for the cox 1 consisted of $95^{\circ} \mathrm{C}$ for $2 \mathrm{~min}$, followed by $40 \mathrm{cy}$ cles of $95{ }^{\circ} \mathrm{C}$ for $30 \mathrm{~s}, 52{ }^{\circ} \mathrm{C}$ for $50 \mathrm{~s}$, and $72{ }^{\circ} \mathrm{C}$ for $30 \mathrm{~s}$, and a final extension at $72{ }^{\circ} \mathrm{C}$ for $5 \mathrm{~min}$.

It was necessary to amplify and sequence the nad5 region of the mitochondrial DNA of a subset of the confirmed Onchocerca-positive blackflies from the 2015 collection, because there was no information available on the cox1 region of the cryptic Onchocerca found in white-tailed deer from upstate New York [7]. Briefly, nad5 PCR reactions followed the same protocol, using the primers ND5-Ov5A-F (5'-TTG GTT GCC TAA GGC TAT GG-3') and ND5OvC-R (5'-CCC CTA GTA AAC AAC AAA CCA CA-3') [24]. Cycling conditions for the ND5 region consisted of $95^{\circ} \mathrm{C}$ for 2 min, followed by 35 cycles of $95^{\circ} \mathrm{C}$ for $30 \mathrm{~s}, 50^{\circ} \mathrm{C}$ for $45 \mathrm{~s}$, and $72{ }^{\circ} \mathrm{C}$ for $30 \mathrm{~s}$, and a final extension at $72{ }^{\circ} \mathrm{C}$ for $5 \mathrm{~min}$.

\section{6 collections}

All 2016 extractions followed the same protocol of maceration and incubation in ATL buffer and proteinase K; however, all following steps of the DNA extraction protocols were performed manually following the manufacturer's protocol.

For specimens morphologically identified as Simulium tescorum, we performed individual DNA extractions, for each head and body, separately. Because of the high number of Simulium vittatum-complex specimens, heads and bodies were extracted separately, and samples consisted from individual flies (i.e. single fly caught in a trap) to pools of up to 10 flies. Pools consisted of flies caught in the same trap, separated by species. All 2016 samples were screened using the above described PCR reaction targeting the nad5 region of the mtDNA.

\section{Blood-meal analysis}

A subset of 36 S. tescorum from the 2015 collections, considered potentially engorged, were screened for the host blood meal using a PCR targeting the $16 S$ rRNA of vertebrates [25]. PCR reactions followed the previous mentioned protocol, using the primers L2513-F (5'-GCC TGT TTA CCA AAA ACA TCC-3') and H2714-R (5'-CTC CAT AGG GTC TTC TCG TCT T-3'). Cycling conditions consisted of $95{ }^{\circ} \mathrm{C}$ for $4 \mathrm{~min}$, followed by 35 cycles of $95{ }^{\circ} \mathrm{C}$ for $30 \mathrm{~s}, 57^{\circ} \mathrm{C}$ for $30 \mathrm{~s}$, and $72{ }^{\circ} \mathrm{C}$ for 30 $\mathrm{s}$, and a final extension at $72{ }^{\circ} \mathrm{C}$ for $10 \mathrm{~min}$.

\section{Sequencing}

All PCR products of samples that produced amplicons visualized in the agarose gel, were column purified using the Kit Cycle Pure EZNA kit (Omega Bio-Tek, Norcross, GA, USA) following the manufacturer's protocol. Products were then directly sequenced using their respective forward and reverse primers using BigDye Terminator Cycle sequencing.

\section{Phylogenetic analysis}

All sequences were edited individually, and aligned by Clustal W in MEGA 7 [26]. Phylogenetic trees of the cox1 (432 bp) and nad5 (427 bp) sequences were constructed using the Maximum Parsimony method, with 2000 bootstrap replicates. We have included in the phylogenetic analyses sequences of Onchocerca species 
available in GenBank. Sequences of Dirofilaria immitis (Leidy, 1856) and Dirofilaria repens Railliet \& Henry, 1911, which also belong to the family Onchocercidae, were included as outgroups [27].

\section{Taxonomy of simuliid vectors and mammalian hosts for Onchocerca}

The taxonomy of blackflies followed the most recent and comprehensive literature [22, 28]. Taxonomy of artiodactyl mammalian hosts for Onchocerca and other filarioid taxa followed Grubb (2005) [29].

\section{Results}

\section{Collections}

A total of 1056 blackflies was collected during the 2015 collections; of these, 1039 were collected from 34 sites within the SGVMVCD area, with 683 (65.7\%) identified as species of the S. vittatum (s.l.) and $373(34.3 \%)$ as $S$. tescorum (Fig. 1). Seventeen blackflies collected from six sites by the GLACVCD were not morphologically identified to the species/species-complex level.
In the 2016 collections, a total of 378 host-seeking female blackflies was collected from 23 sites in the SGVMVCD area and 8 sites in the GLACVCD (Fig. 1). Out of the 370 blackfly specimens in the San Gabriel Valley, 327 specimens $(88.4 \%)$ were identified as $S$. vittatum-complex and $43(11.6 \%)$ as S. tescorum.

\section{Onchocerca screening}

Regarding the 2015 collections, a total of 18 (1.7\%) blackflies collected in 2015 was positive for Onchocerca DNA. Of these, 17 were $S$. tescorum (4.8\%), and one $S$. vittatum-complex $(0.2 \%)$. The cox 1 sequences did not match any species of Onchocerca available in GenBank. Hence, a subset of these samples had their nad5 region amplified and sequenced.

Out of the S. tescorum samples, 11 were collected from a single location along the San Gabriel River in Azusa, were Onchocerca-positive in March $(n=7)$, July $(n=3)$ and August $(n=1)$. Five Onchocerca-positive $S$. tescorum were collected from three locations in Glendora, in the months of April $(n=3)$, May $(n=1)$ and

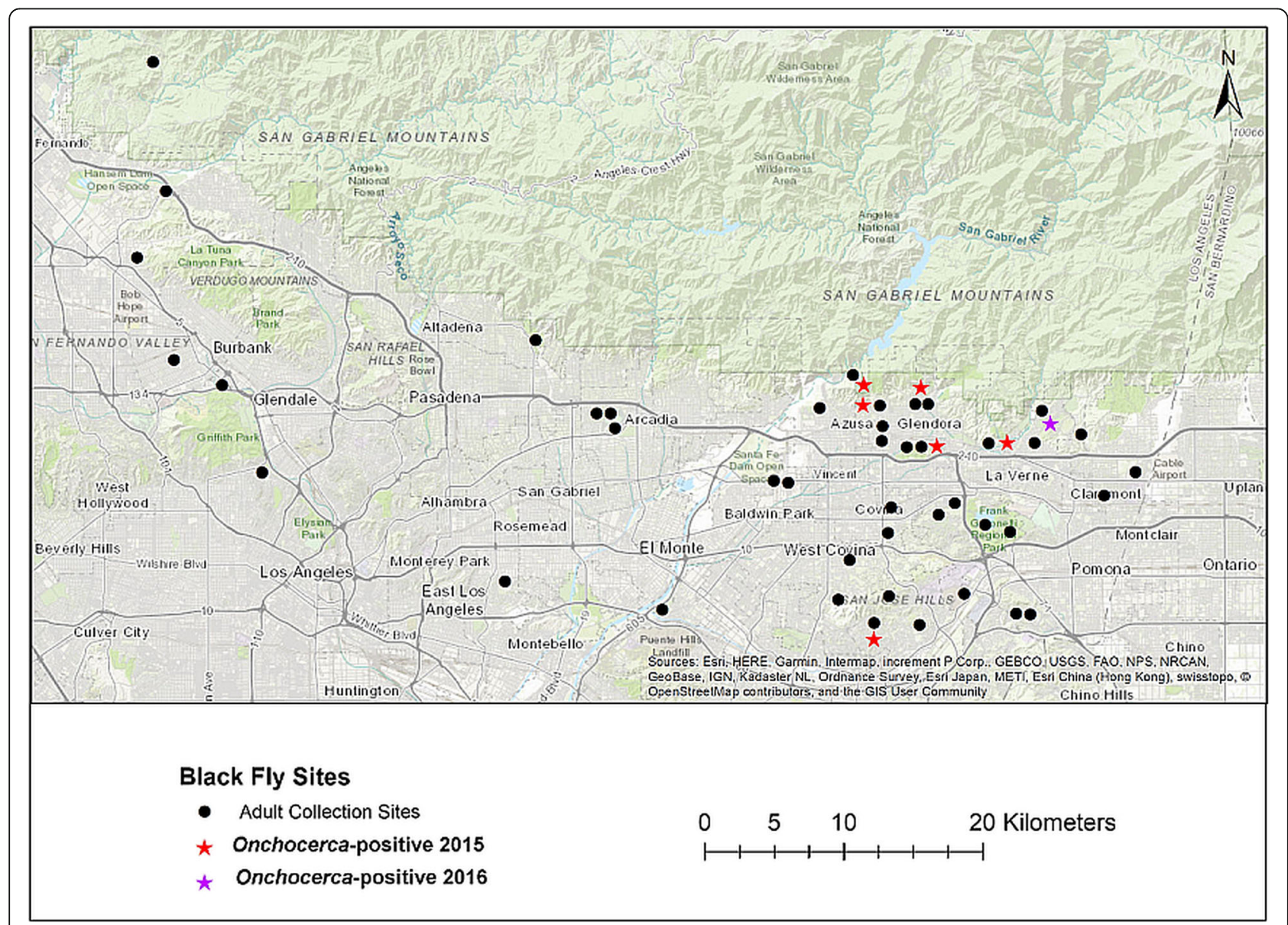

Fig. 1 Adult blackfly collection sites in Los Angeles County, California. Adult blackflies that tested positive for the uncharacterized Onchocerca sp. in $2015(n=6)$ are indicated by a red star, and the single Onchocerca-positive sample in $2016(n=1)$ is indicated by a purple star. 
July $(n=1)$, and the remaining positive was from Walnut, CA in June. The only Onchocerca-positive $S$. vittatum (s.l.) was collected in San Dimas, California in April.

From the 2016 samples, all 43 individual heads of $S$. tescorum and 67 pools of heads of S. vittatum (s.l.) were negative for Onchocerca DNA. Screening of heads was performed because they are likely to harbor third-stage larvae (L3) of Onchocerca, following recommendations for molecular xenodiagnosis/entomological surveillance of O. volvulus in blackflies in sub-Saharan Africa or Latin American foci [30].

A single pool of S. vittatum (s.l.) bodies collected in April from La Verne was confirmed positive for the uncharacterized Onchocerca. All bodies of S. tescorum were negative for Onchocerca DNA. The locations where Onchocerca-positive blackflies were found can be seen in Fig. 1.

\section{Blood-meal analysis}

A subset 36 blackflies from the 2015 collections was screened for the host blood meal using PCR targeting the $16 S$ rRNA of vertebrates, with one positive for Cervidae DNA. A single S. tescorum, which was positive for Onchocerca DNA, resulted in a 195 bp fragment sequenced, is 99\% identical to sequences of mule deer, white-tailed deer, mule deer and red brocket deer Mazama americana (Erxleben), with only a single nucleotide deletion. No PCR amplification was obtained from other 35 blackflies. Based on the sequence identity comparison using the BLAST tool, we could not unequivocally identify the host species. However, only the mule deer naturally occurs in the Los Angeles County, and southern California, USA.

\section{Phylogenetic analysis}

All generated cox 1 sequences were deposited in the GenBank database (MH370234-MH370251). The phylogenetic analysis, based on cox1 sequences, showed that all isolates formed a well-supported (99 bootstrap support), reciprocally monophyletic clade (Fig. 2), and belong to an uncharacterized species of Onchocerca. Pairwise distances among the cox 1 sequences generated for the cryptic species varied from 0 to 0.012 (average 0.004), and there were only 6 variable sites.

Since there was no information on the $\operatorname{cox} 1$ sequences of the putative cryptic Onchocerca species in white-tailed deer from upstate New York, we also performed phylogenetic reconstruction based on the nad5 region. Pairwise-distance among the nad5 among LA isolates ranged between 0-0.025 (average 0.005), with 10 variable sites. Pairwise distances among the LA and NY isolates ranged between 0.011-0.016 (average 0.012), further supporting that these are conspecific.

Similarly, all generated nad5 sequences were deposited in the GenBank database (MH370252-MH370264).
Phylogenetic analysis based on nad5 sequences showed that all isolates formed a well-supported clade ( 95 bootstrap support). The sister group were the NY isolates, which also formed a well-supported clade (92 bootstrap support) (Fig. 3).

\section{Discussion}

We have found DNA of a cryptic species of Onchocerca in two species of blackflies, S. tescorum and S. vittatum (s.l.) (Simulium tribulatum Lugger), from LAC, southern California, USA. Phylogenetic analyses demonstrated that these samples and populations appear conspecific with a recently discovered and undescribed species of Onchocerca infecting WTD in the northeastern USA [7]. Combined, these isolates from LAC and those from New York formed a well-supported monophyletic clade (92 bootstrap support) and demonstrated minimal divergence in $n a d 5$ sequences.

To date in North America only one species, O. cervipedis, has been formally described and has been reported to infect five species of cervids and the pronghorn $[8,11,12]$. Our work provides further evidence for the existence of a cryptic, undescribed species of Onchocerca associated with wild ungulates in North America [7]. Onchocerca cervipedis should now be recognized as a species complex; and hence, all previous host and geographical reports should be cautiously interpreted. The broad host range for O. cervipedis (s.l.) is atypical among species of Onchocerca, with only a few species known to infect multiple hosts [1]. The $O$. cervipedis species complex encompasses an extensive geographical distribution, ranging from tropical forests in Costa Rica, Central America [10] to subarctic environs of northern North America [11]. The original description of O. cervipedis by Wehr \& Dikmans [8] was based on specimens collected from the subcutaneous tissues of the hindquarters, ankles and foot of two hosts and localities: white-tailed deer from Montana, USA, and Columbia black-tailed deer (O. h. columbianus) from British Columbia, Canada. There is a need to reassess the type-material of $O$. cervipedis, and to further characterize specimens collected from the two hosts, and ideally from the original localities using integrated classical and molecular tools. At this stage, it cannot be determined if either O. cervipedis sensu Verocai et al., 2012 [11] or the cryptic species isolated in the present study and in the skin of WTD in New York belong to O. cervipedis as originally described. The potential for zoonotic infections among species of Onchocerca establishes the need to characterize the recently recognized cryptic species, to explore for broader currently hidden diversity and to define the host and geographical limits within this assemblage.

In parallel, the recent discovery of a cryptic species of Onchocerca infecting white-tailed deer from upstate New York [7] was based on molecular evidence only. In contrast to our study, these conspecific parasites were 


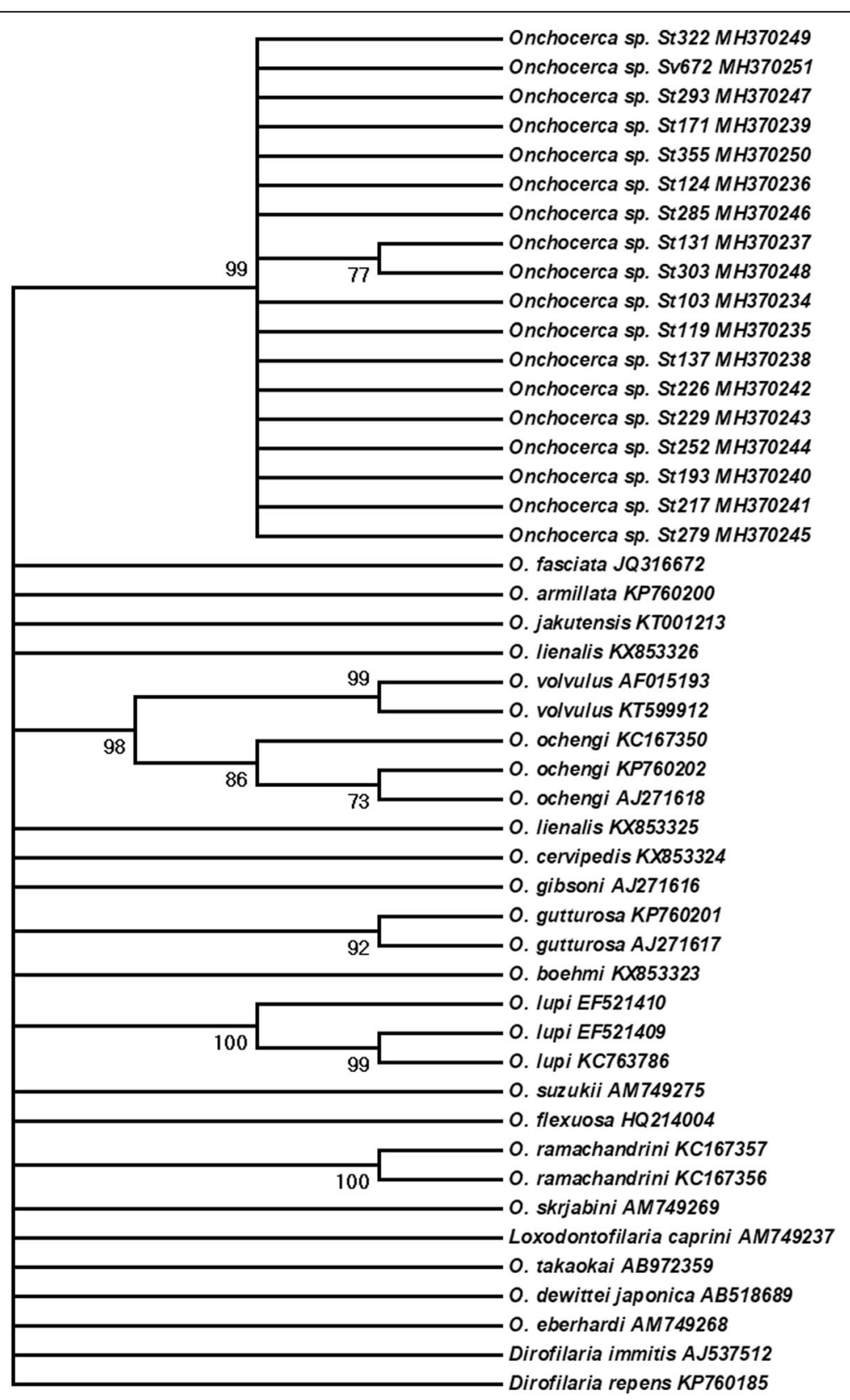

Fig. 2 Maximum Parsimony tree depicting phylogenetic relationships among species of Onchocerca inferred from cytochrome $c$ oxidase subunit 1 (cox1) mitochondrial gene. Branches with less than 70\% bootstrap support were collapsed. Bootstrap support shown besides branches are based on 2000 replicates. All sequences labeled as Onchocerca sp. were obtained from blackflies from the Los Angeles County, southern California, and have been accessioned at GenBank (MH370234-MH370251). The codes Sv and St refer to Simulium vittatum (s.l.) and S. tescorum, respectively, from which each DNA sequence was obtained

revealed through sequencing of microfilariae in skin samples from deer. The effectiveness of surveillance based on screening of samples derived from definitive hosts or from arthropod vectors is established and provides the foundation to explore transmission dynamics from landscape to broader geographical scales. Although clearly established as a previously unrecognized species based on larval parasites, adult specimens in cervid definitive hosts have yet to be collected and described; formal description including all life history stages remains pending.

Vector screening for cryptic diversity

Our results demonstrate that sampling and molecular screening of putative arthropod vectors is an effective path for recognizing cryptic vector-borne parasites. These methods provide for geographically 


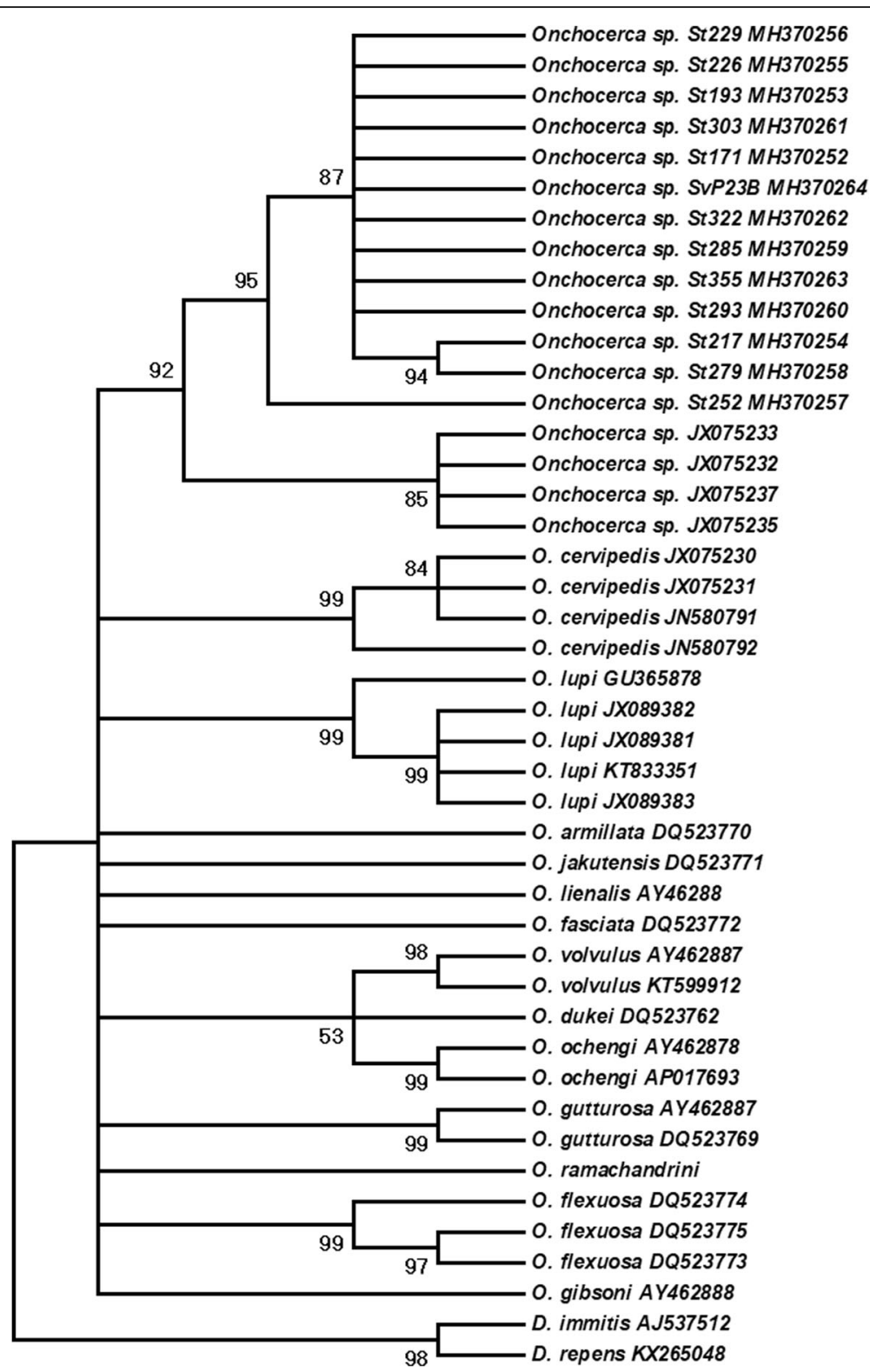

Fig. 3 Maximum Parsimony tree depicting phylogenetic relationships among species of Onchocerca inferred from the NADH dehydrogenase subunit 5 (nad5) mitochondrial gene. Branches with less than $70 \%$ bootstrap support were collapsed. Bootstrap support shown besides branches are based on 2000 replicates. All sequences labeled as Onchocerca sp. followed by the codes Sv or St were obtained from blackflies from the Los Angeles County, southern California, and have been accessioned at GenBank (MH370252-MH370264). Sv and St refer to Simulium vittatum (s.I.), and S. tescorum, respectively, from which each DNA sequence was obtained. The code SVP23B refers to a pool of S. vittatum (s.l.) bodies. Sequences labeled as Onchocerca sp. followed by GenBank accession numbers JX075232, JX075233, JX075235 and JX075237 originated from upstate New York, and were made available through McFrederick et al. [7]

widespread and site intensive sampling without requiring either invasive host sampling (i.e. in the case of Onchocerca, skin biopsy) or labor-intensive postmortem examinations (i.e. fecal examinations for gastrointestinal and pulmonary parasites) [31, 32] Nevertheless, relevant geographical records, and putative information on host and vector associations may be acquired.
The overall prevalence of Onchocerca DNA in both blackfly species was low, but similar to the prevalence for O. lupi found in S. tribulatum from the same area [20]. Our findings suggest that S. tescorum and S. vittatum (s.l.) are putative vectors for this cryptic Onchocerca. Host-seeking blackflies are either autogenous seeking a blood meal after their first oviposition or have fed a few days ago (e.g. $72 \mathrm{~h}$ for S. damnosum (s.l.) [33]). 
The vast majority of collected flies were visually identified as not blood-fed, suggesting that the detected DNA could belong to larval stages undergoing development within the vector (L1 to L3), and not freshly ingested microfilariae. In addition, we failed to find Onchocerca DNA in the heads of both Simulium species from the 2016 collections, which could indicate the presence of infective L3 in the mouthparts of the fly. These negative results could confirm the competence of these blackfly species in transmission of the cryptic species of Onchocerca; hence these are considered putative vectors. However, the 2016 collections yielded much lower numbers of flies comparing to the 2015 collections, and overall low prevalence of Onchocerca.

Only a few blackfly species have been documented as putative vectors of $O$. cervipedis (s.l.) in North America; however, these few studies lack molecular confirmation of species identity of the nematode. Prosimulium impostor Peterson is the putative vector of a deer-associated Onchocerca in California [34], and Simulium decorum Walker and Simulium venustum Say are putative vectors for $O$. cervipedis among moose from northeastern Alberta, Canada [35]. The two putative vectors found in the present study differ significantly in their geographical distribution. Species within the Simulium vittatum complex, in particular S. tribulatum, are widely distributed across North America including areas of the northeastern USA where the cryptic Onchocerca has been reported $[7,22]$. In contrast, the range of $S$. tescorum seems restricted to southern California and New Mexico [22], and therefore it may only play a role in transmission of the cryptic Onchocerca in the studied area. Nevertheless, since we now know that the North American Onchocerca diversity is higher than previously thought, the vector associations previously assumed for O. cervipedis should be reassessed across the continent using molecular methods. Concurrently, specimens of putative arthropod vectors should be routinely archived in museum collections as appropriate (e.g. when methods used are not destructive) as a basis to confirm identification and as baselines to allow assessment of ongoing ecological changes and shifts in distribution over time.

The presence of DNA of this cryptic Onchocerca species in blackflies also provides relevant information on the ecology of these blackflies, suggesting that both feed on cervids, with the mule deer being the only cervid endemic to LAC. Simulium tescorum is mammalophic and has been reported biting and potentially feeding on bighorn sheep (Ovis canadensis Shaw) and humans [36, 37]. The species of the $S$. vittatum complex in southern California is $S$. tribulatum, also a mammalophilic species, has been reported to feed on horses and cattle [22], and also to feed in ears of bighorn sheep [36]. This species is also known to feed on humans in the LAC (K. Nelson, personal communication). Our only successful blood-meal analysis showed DNA of Odocoileus, likely mule deer. Most studies on wild caught blackflies using $\mathrm{CO}_{2}$-baited traps are able to recover only a small percentage of blood-fed flies, and can be as low as 1 to $3-$ 1000 flies [38, 39]. Indeed, our trapping strategy did not target blood-fed blackflies, which are in general less active than host-seeking flies, and less likely to be attracted to $\mathrm{CO}_{2}$ traps. The finding of blood-fed females may suggest an interrupted blood meal or that the fly was caught by chance (i.e. not necessarily attracted by the $\mathrm{CO}_{2}$ ) Also, the time after a blood meal may directly influence the sensitivity of a molecular assay. Blood meals ingested by Simulium damnsosum (s.l.) blackflies may not be detectable after two days due to complete digestion of blood and DNA degradation [33].

The only confirmed reports of another species of Onchocerca, based on molecular sequence data, in the southwestern USA, are for the zoonotic O. lupi [20, 4044]. In the LAC, O. lupi was found in clinical canine cases of ocular onchocercosis and in S. tribulatum, which was then considered a putative vector for this species. Besides O. lupi, there have been reports of other species of Onchocerca associated with wild cervids (Onchocerca jakutensis (Gubanov, 1964)) and suids (Onchocerca dewittei japonica Uni, Bain \& Takaoka, 2001) in humans, and therefore, other blackfly-transmitted Onchocerca species may also pose a potential zoonotic threat [45-47]. Climate envelopes may determine the geographical distributions of potential blackfly and related arthropod vectors, and accelerating climate warming and habitat change have considerable potential to modify the ranges of vector-borne host-parasite assemblages [48, 49]. Habitat disruption drives changing opportunities for transmission and may result in altered patterns of exposure and infection for species of Onchocerca among otherwise naïve and potential hosts such as other ungulates and humans. Opportunity and broad capacities for parasites to utilize host resources as defined by ecological fitting are anticipated to lead to broadened infection and emergence of disease in these and other host-parasite systems $[50,51]$. Such considerations provide the rationale for continued efforts for the discovery of pathogen diversity, exploration of phylogeny and history, surveillance, monitoring and development of actionable information to limit the impact of emerging infectious disease in this arena of accelerating perturbation [52].

\section{Phylogenetic considerations, and evidence for a complex historical biogeography of Onchocerca in North America} Our intention was not to explore phylogenetic relationships in the broader context for the genus Onchocerca 
but to unequivocally identify this taxon in comparison with the two previously characterized isolates in North American cervids based on molecular data. Collectively, these constitute the limits so far recognized within the species complex for $O$. cervipedis $[1,7,11]$. In this limited comparative context, phylogenetic reconstruction based on cox1 and nad5 suggested that the cryptic Onchocerca species found in this study does not belong to the same taxon as $O$. cervipedis (s.l.) [11]. Further, in a recent phylogenetic study based on three mitochondrial genes (nad5, 12S, and 16S) [7], the cryptic species of Onchocerca was shown to be the putative sister taxon to Onchocerca lienalis (Stiles, 1892), a parasite of domestic cattle. This relationship could not be confirmed in the current analyses due to basal polytomies in both gene trees. The most comprehensive phylogenetic framework for the genus included $O$. lienalis among other cattle-associated species and in the same clade as Onchocerca volvulus of humans, and the zoonotic O. lupi [1]. Existing evidence supports the hypothesis that the two North American species of Onchocerca; i.e. O. cervipedis sensu Verocai et al., 2012 [11] and the cryptic species [7] represents the outcomes of independent expansion events with ungulate hosts across the Bering Landbridge from Eurasia in the Pliocene or Pleistocene [53]. Subsequent host associations may reflect a history of colonization and speciation. This pattern leading to assembly of a faunal mosaic is similar to that recognized among other mammalian- parasitic nematode assemblages in North America [53, 54], including Varestrongylus lungworms associated with cervids, and Uncinaria hookworms associated with bears, among others [55-61].

Based on geographical and putative host associations of the cryptic species of Onchocerca, we are able to make inferences on its historical biogeography. The existing records from two distant corners of the USA, southern California and upstate New York, support recognition of a widespread geographical distribution. Such reports also suggest that this species likely infects at least two species of Odocoileus including in areas in which these species do not co-occur. For example, the two subspecies of mule deer, $O . h$. californicus and $O$. $h$. fuliginatus, are endemic to southern California, and overall the species ranges across much of western North America, but is absent in the northeast [21]. In contrast, WTD is broadly distributed across eastern portions of western North America, excluding most of California, and extends southwards into northern South America [62].

\section{Conclusions}

An uncharacterized Onchocerca species associated with cervid hosts was found in blackflies from southern California, USA. This species was previously found in WTD from upstate New York, and hence it supports a broad geographical distribution across North America. This considerable range, and knowledge of the geographical ranges of species of Odocoileus suggests that this cryptic Onchocerca may infect both white-tailed and mule deer. Simulium tescorum and S. vittatum (s.l.) (presumably S. tribulatum) of blackflies are putative vectors. The biodiversity, definitive host and vector associations of Onchocerca species in North America must be reassessed by means of a comprehensive, continental-scale study based on integrated classical and molecular approaches.

\section{Acknowledgments \\ We would like to thank Bryan Sorvillo and the 2015 and 2016 surveillance teams at the San Gabriel Valley Mosquito and Vector Control District who helped with this project. We are grateful for the collaborative work and support from Paul O'Connor (Greater Los Angeles County Vector Control District), Emily Beeler (Veterinary Public Health Program, Los Angeles County Department of Public Health), Thomas R. Unnasch (University of South Florida, Department of Global Health). \\ Funding \\ This study was supported by the National Center for Veterinary Parasitology. \\ Availability of data and materials \\ The data supporting the conclusions of this article are included within the article. The sequences have been submitted to the GenBank database under the accession numbers MH370234-MH370251 (cox1) and MH370252- MH370264 (nad5)}

\section{Authors' contributions}

GGV acquired funding and drafted the manuscript. KJN and JWW performed blackfly collections and identification. GV, RTC and HKH performed the molecular genetic study. EPH contributed with aspects on the historical biogeography and phylogeny. All authors read and approved the final manuscript.

\section{Ethics approval and consent to participate}

Not applicable.

\section{Consent for publication}

Not applicable.

\section{Competing interests}

The authors declare that they have no competing interests.

\section{Publisher's Note}

Springer Nature remains neutral with regard to jurisdictional claims in published maps and institutional affiliations.

\section{Author details}

${ }^{1}$ Department of Infectious Diseases, College of Veterinary Medicine, University of Georgia, 501 D.W. Brooks Drive, Athens, GA 30602, USA. ${ }^{2}$ Department of Global Health, College of Public Health, University of South Florida, 3720 Spectrum Boulevard, Tampa, FL 33612, USA. ${ }^{3}$ San Gabriel Valley Mosquito and Vector Control District, 1145 N. Azusa Canyon Rd, West Covina, CA 91790, USA. ${ }^{4}$ Coachella Valley Mosquito and Vector Control District, 43420 Trader Place, Indio, CA 92201, USA. ${ }^{5}$ School of Veterinary Medicine,

Department of Pathobiological Sciences, University of Wisconsin, Madison, WI 53706, USA.

Received: 31 May 2018 Accepted: 2 October 2018 Published online: 16 October 2018

\section{References}

1. Lefoulon E, Giannelli A, Makepeace BL, Mutafchiev Y, Townson S, Uni S, et al. Whence river blindness? The domestication of mammals and hostparasite coevolution in the nematode genus Onchocerca. Int J Parasitol. 2017:47:457-70 
2. Anderson RC. Nematode Parasites of Vertebrates. Their Development and Transmission. Wallingford: CABI Publishing; 2000.

3. Bain O. Le genre Onchocerca: Hypothèses sur son évolution et clé dichotomique des espèces. Ann Parasitol Hum Comp. 1981;56:503-26.

4. Uni S, Bain O, Agatsuma T, Harada M, Torii H, Fukuda M, Takaoka H. Onchocerca eberhardi n. sp. (Nematoda: Filarioidea) from sika deer in Japan; relationships between species parasitic in cervids and bovids in the Holarctic region. Parasite. 2007;14:199-211.

5. Uni S, Fukuda M, Agatsuma T, Bain O, Otsuka Y, Nakatani J, et al. Onchocerca takaokai n. sp. (Nematoda: Filarioidea) in Japanese wild boars (Sus scrofa leucomystax): description and molecular identification of intradermal females. Parasitol Int. 2015;64:493-502.

6. Yagi K, Bain O, Shoho C. Onchocerca suzukii n. sp. and Onchocerca skrjabini $(=0$. tarsicola) from a relict bovid, Capricornis crispus, in Japan. Parasite. 1994;1:349-56.

7. McFrederick QS, Haselkorn TS, Verocai GG, Jaenicke J. Cryptic Onchocerca species infecting North American cervids, with implications for the evolutionary history of host association in Onchocerca. Parasitology. 2013;140:1201-10.

8. Wehr EE, Dikmans G. New nematodes (Filariidae) from North America ruminants. Zool Anz. 1935;110:202-8.

9. Caballero YC. Morfologia y posicion sistematica de Onchocerca cervipedis. Rev Bras Biol. 1954;4-5:557-62.

10. Carreno RA, Durden LA, Brooks DR, Abrams A, Hoberg EP. Parelaphostrongylus tenuis (Nematoda: Protostrongylidae) and other parasites of white-tailed deer (Odocoileus virginianus) in Costa Rica. Comp Parasitol. 2001;68:177-84.

11. Verocai GG, Lejeune M, Beckmen KB, Kashivakura CK, Veitch AM, Popko R, et al. Defining parasite biodiversity at high latitudes of North America: new host and geographic records for Onchocerca cervipedis (Nematoda: Onchocercidae) in moose and caribou. Parasit Vectors. 2012;5:242.

12. Dikmans G. Onchocerca flexuosa from the subcutaneous tissues of an antelope and subcutaneous abscesses of a deer. J Parasitol. 1933;19:246.

13. Low WA. Parasites of woodland caribou in Tweedsmuir Provincial Park, British Columbia. Can Field-Nat. 1976;90:189-91.

14. De Nio RM, West RM. The foot-worm disease in deer on the Northern Rocky Mountain Region. J Forest. 1942;40:540-3.

15. Herman CM, Bischoff Al. The footworm parasite of deer. Calif Fish Game. 1946;32:182-90.

16. Ritcey RW, Edwards RY. Parasites and diseases of the Wells Gray moose herd. J Mammal. 1958;39:139-45.

17. Rush WM. Onchocerciasis: a new disease in the white-tailed deer of Montana. J Mammal. 1935;16:70-1.

18. Samuel WM, Barrett MW, Lynch GM. Helminths in moose of Alberta. Can J Zool. 1976;54:307-12.

19. Williams RB, Babero BB. Onchocerca in an Alaskan moose. J Mammal. 1958 39:449-50.

20. Hassan HK, Bolcen S, Kubofcik J, Nutman TB, Eberhard ML, Middleton K, et al. Isolation of Onchocerca lupi in dogs and ies, California, USA. Emerg Infect Dis. 2015;21:789-96.

21. Sanchez Rojas G, Gallina Tessaro S. Odocoileus hemionus. The IUCN Red List of Threatened Species. 2016. www.iucnredlist.org/pdflink.22162113. Accessed 11 May 2018.

22. Adler PH, Currie DC, Wood M. The black flies (Simuliidae) of North America. New York: Comstock Books; 2004.

23. Casiraghi M, Anderson TJC, Bandi C, Bazzocchi C, Genchi C. A phylogenetic analysis of filarial nematodes: comparison with the phylogeny of Wolbachia endosymbionts. Parasitology. 2001:122:93-103.

24. Morales-Hojas R, Checke RA, Post RJ. Molecular systematics of five Onchocerca species (Nematoda: Filarioidea) including the human parasite, $\mathrm{O}$. volvulus, suggest sympatric speciation. J Helminthol. 2006;80:281-90.

25. Kitano T, Umetsu K, Tian W, Osawa M. Two universal primer sets for species identification among vertebrates. Int J Legal Med. 2007;121:423-7.

26. Kumar S, Stecher G, Tamura K. MEGA7: Molecular Evolutionary Genetics Analysis version 7.0 for bigger datasets. Mol Biol Evol. 2016;33:1870-4.

27. Lefoulon E, Bain O, Bourret J, Junker K, Guerrero R, Cañizales I, et al. Shaking the tree: multi-locus sequence typing usurps current onchocercid (filarial nematode) phylogeny. PLoS Negl Trop Dis. 2015;9:e0004233.

28. Adler PH, Crosskey RW. World blackflies (Diptera: Simuliidae): A comprehensive revision of the taxonomic and geographical inventory. 2018. https://biomia. sites.clemson.edu/pdfs/blackflyinventory.pdf. Accessed 11 May 2018.

29. Grubb P. Order Artiodactyla. In: Wilson DE, Reeder DM, editors. Mammal Species of the World: A Taxonomic and Geographic Reference. Baltimore: The Johns Hopkins University Press; 2005. p. 652-722.
30. WHO. Guidelines for stopping mass drug administration and verifying elimination of human onchocerciasis. Geneva: World Health Organization; 2016. www.who. int/onchocerciasis/resources/9789241510011/en/. Accessed 20 April 2018

31. Verocai GG. Contributions to the biodiversity and biogeography of the genus Varestrongylus Bhalerao, 1932 (Nematoda: Protostrongylidae), lungworms of ungulates, with emphasis on a new Nearctic species. PhD thesis, University of Calgary, Calgary; 2015.

32. Kutz SJ, Asmundsson I, Hoberg EP, Appleyard GD, Jenkins EJ, Beckmen K, et al. Serendipitous discovery of a novel protostrongylid (Nematoda: Metastrongyloidea) in caribou, muskoxen, and moose from high latitudes of North America based on DNA sequence comparisons. Can J Zool. 2007:85:1143-56.

33. Boakye DA, Tang J, Truc P, Merriweather A, Unnasch TR. Indentification of bloodmeals in haematophagous Diptera by cytochrome B heteroduplex analysis. Med Vet Entomol. 1999;13:282-7.

34. Weinmann CJ, Anderson JR, Longhurst WM, Conolly G. Filarial worms of Columbian black-tailed deer in California I. Observations in the vertebrate host. J Wildl Dis. 1973:9:213-20.

35. Pledger DJ. Black flies (Diptera, Simuliidae) of the Swan Hills, Alberta, as possible vectors of Onchocerca cervipedis Wehr \& Dikmans 1935 (Nematoda; Onchocercidae) in moose (Alces alces Linnaeus). MSci Thesis, University of Alberta, Edmonton; 1978.

36. Mullens BA, Dada CE. Insects feeding on desert bighorn sheep, domestic rabbits, and Japanese quail in the Santa Rosa Mountains of southern California. J Wildl Dis. 1992;28:476-80.

37. Lacey LA, Mulla MS. Observations on the biology and distribution of Simulium tescorum (Diptera: Simuliidae) in California and adjacent areas. Pan-Pacific Entomol. 1980;56:323-31.

38. Malmqvist B, Strasevicius D, Hellgren O, Adler PH, Bensch S. Vertebrate host specificity of wildcaught blackflies revealed by mitochondrial DNA in blood. Proc Royal Soc B. 2004;271:S152-5.

39. Hunter FF, Bayly R. ELISA for identification of blood meal source in black flies (Diptera, Simuliidae). J Med Entomol. 1991;7:105-10.

40. Labelle AL, Maddox CW, Daniels JB, Lanka S, Eggett TE, Dubielzig RR, Labelle $P$. Canine ocular onchocercosis in the United States is associated with Onchocerca lupi. Vet Parasitol. 2013;193:297-301.

41. Otranto D, Giannelli A, Latrofa MS, Dantas-Torres F, Trumble NS, Chavkin M, et al. Canine infections with Onchocerca lupi nematodes, United States, 2011-2014. Emerg Infect Dis. 2015;21:868-71.

42. Otranto D, Giannelli A, Trumble NS, Chavkin M, Kennard G, Latrofa MS, et al. Clinical case presentation and a review of the literature of canine onchocercosis by Onchocerca lupi in the United States. Parasit Vectors. 2015;8:89.

43. McLean NJ, Newkirk K, Adema CM. Canine ocular onchocerciasis: a retrospective review of the diagnosis, treatment, and outcome of 16 cases in New Mexico (2011-2015). Vet Ophthalmol. 2017;20:349-56.

44. Cantey PT, Weeks J, Edwards M, Rao S, Ostovar GA, Dehority W, et al. The emergence of zoonotic Onchocerca lupi infection in the United States - a case-series. Clin Infect Dis. 2016:62:778-83.

45. Koehsler M, Soleiman A, Aspöck H, Auer H, Walochnik J. Onchocerca jakutensis filariasis in humans. Emerg Infect Dis. 2007;13:1749-52.

46. Takaoka H, Bain O, Tajimi S, Kashima K, Nakayama I, Korenaga M, et al. Second case of zoonotic Onchocerca infection in a resident of Oita in Japan. Parasite. 1996;3:179-82.

47. Takaoka H, Fukuda M, Otsuka Y, Aoki C, Uni S, Bain O. Blackfly vectors of zoonotic onchocerciasis in Japan. Med Vet Entomol. 2012;26:372-8.

48. Laaksonen S, Oksanen A, Hoberg E. A lymphatic dwelling filarioid nematode, Rumenfilaria andersoni (Filarioidea; Splendidofilariinae), is an emerging parasite in Finnish cervids. Parasit Vectors. 2015;8:228.

49. Hoberg EP, Brooks DR. Evolution in action: Climate change, biodiversity dynamics and emerging infectious disease. Philos Trans Royal Soc B. 2015;370:20130553.

50. Agosta SJ, Janz N, Brooks DR. How specialists can be generalists: resolving the "parasite paradox" and implications for emerging infectious disease. Zoologia. 2010;27:151-62.

51. Araújo SBL, Braga MP, Brooks DR, Agosta S, Hoberg EP, von Hathental F, Boeger WA. Understanding host-switching by ecological fitting. PLoS One. 2015;10:e0139225

52. Brooks DR, Hoberg EP, Boeger WA, Gardner SL, Galbreath KE, Herczeg D, et al. Finding them before they find us: informatics, parasites, and environments in accelerating climate change. Comp Parasitol. 2014;81:155-64.

53. Hoberg EP, Galbreath KE, Cook JA, Kutz SJ, Polley L. Northern host-parasite assemblages: history and biogeography on the borderlands of episodic climate and environmental transition. Adv Parasitol. 2012;79:1-97. 
54. Hoberg EP, Cook JA, Agosta SJ, Boerger W, Galbreath KE, Laaksonen S, et al. Arctic systems in the Quaternary: ecological collision, faunal mosaics and the consequences of a wobbling climate. J Helminthol. 2017;91:409-21.

55. Hoberg EP. Invasive processes, mosaics and the structure of helminth parasite faunas. Rev Sci Tech OIE. 2010;29:255-72.

56. Hoberg EP, Brooks DR. Beyond vicariance: Integrating taxon pulses, ecological fitting and oscillation in historical biogeography and evolution. In: Morand S, Krasnov B, editors. The Geography of Host-Parasite Interactions. Oxford: Oxford University Press; 2010. p. 7-20.

57. Verocai GG, Hoberg EP, Vikøren T, Handeland K, Ytrehus B, Rezansoff AM, et al. Resurrection and redescription of Varestrongylus alces (Nematoda; Protostrongylidae), a lungworm of the Eurasian moose (Alces alces), with report on associated pathology. Parasit Vectors. 2014;7:556.

58. Verocai GG, Kutz SJ, Simard M, Hoberg EP. Varestrongylus eleguneniensis sp. n. (Nematoda: Protostrongylidae): a widespread, multi-host lungworm of wild North American ungulates, with an emended diagnosis for the genus and explorations of biogeography. Parasit Vectors. 2014;7:557.

59. Catalano S, Lejeune M, van Paridon B, Pagan CA, Wasmuth JD, Tizzani P, et al. Morphological variability and molecular identification of Uncinaria spp (Nematoda; Ancylostomatidae) from grizzly and black bears: new species or phenotypic plasticity? J Parasitol. 2015;101:182-92.

60. Verocai GG, Kutz SJ, Hoberg EP. Varestrongylus (Nematoda; Protostrongylidae), lungworms of ungulates: a phylogenetic framework based on comparative morphology. Parasitol Res. 2018;117:2075-83.

61. Verocai GG, Kutz SJ, Hoberg EP. Historical biogeography among species of Varestrongylus lungworms (Nematoda: Protostrongylidae) in ungulates: episodic expansion and host colonization linking Eurasia and North America. Parasitol Res. 2018;117:2125-37.

62. Gallina S, Lopez Arevalo H. Odocoileus virginianus. The IUCN Red List of Threatened Species. 2016. www.iucnredlist.org/pdflink.10691422. Accessed 11 May 2018.

Ready to submit your research? Choose BMC and benefit from:

- fast, convenient online submission

- thorough peer review by experienced researchers in your field

- rapid publication on acceptance

- support for research data, including large and complex data types

- gold Open Access which fosters wider collaboration and increased citations

- maximum visibility for your research: over $100 \mathrm{M}$ website views per year

At $\mathrm{BMC}$, research is always in progress.

Learn more biomedcentral.com/submissions 